\title{
Desk of the Editor Vol.12 Issue 1
}

\section{Gopinath Kodaganur Srinivaschar ${ }^{1}$}

Published online: 5 February 2021

(C) Indian Association of Surgical Oncology 2021

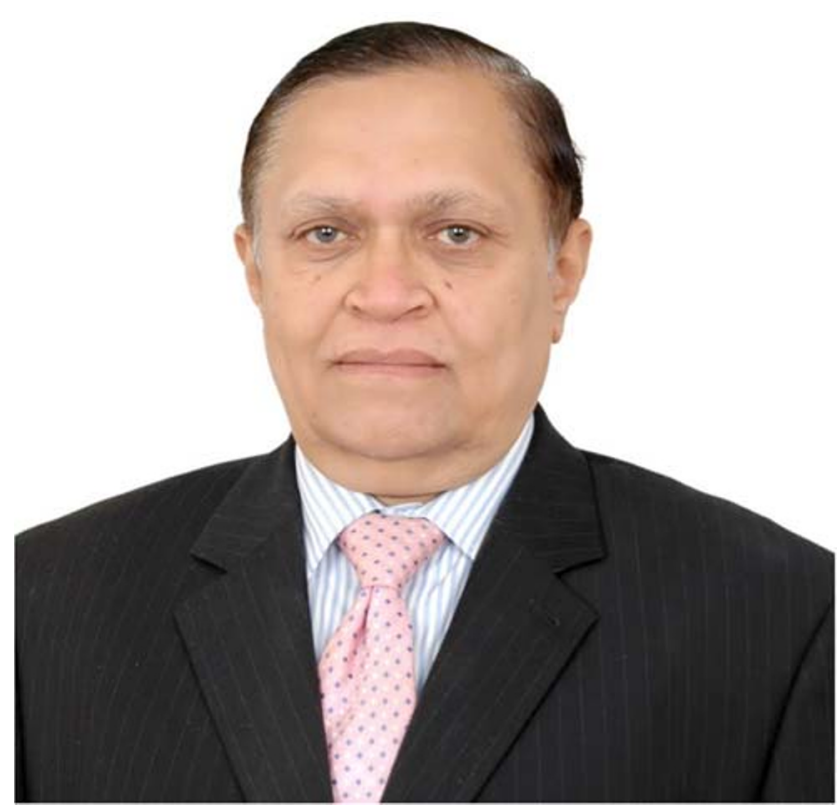

Dear Friends,

Season's greetings and happy New Year 2021.

The old aphorisms "Health is Wealth" is the key buzz word at the present situation, across the Globe.

2019 is the year of Corona pandemic, taught new lessons, to the health professional, public at large, and made people to think, and innovative new ideas \& how to take care of their health.

I am happy to pen down that all institute of oncology both in Govt. and nongovernmental organizations rose to the occasion and worked in explanary manner during Lock Down and continued the standard of care to suffering cancer patients. We learnt there is a need for Prioritizing Cancer Surgeries Amidst

Gopinath Kodaganur Srinivaschar ijso@iasoindia.in

1 HCG, Bangalore Institute of Oncology, Bengaluru, Karnataka, India the COVID-19 Pandemic [2]. This resulted in development of various guidelines by our own association, Institutions and Oncologist to practice evidence based to generate good outcome results [3].

The Indian association of Surgical Oncology took the great lead in this direction, brought out guidelines for the management of oncological disease both to COVID and non COVID patients so that outcome results should not suffer [1].

The Indian journal of surgical oncology now stepping in to 12th year of publication. During COVID, fast track articles were published with short notice enabled medical professionals to further their knowledge.

We have received highest number of submissions nearly 538 articles, across the globe indicating acceptance of the journal by the oncology community. The articles published in IJSO well accepted by the accreditation bodies and the articles were cited during development of guidelines by $\mathrm{ESGO/ESTRO/ESP} \mathrm{guidelines} \mathrm{for} \mathrm{the} \mathrm{management} \mathrm{of} \mathrm{pa-}$ tients with carcinoma Endometrium [3-5].

During this difficult situation, journal offices functioned efficiently and publish four regular issues and two special issues.

We were all aware of problems faced by professional during pandemic and lockdowns. Every individual contributed there might to the society and became "COVID Warriors". We salute them.

Now change of era in 2021, vaccine is going to be introduced and this will make a big difference in public health service to control COVID infection.

$\mathrm{We}$ as a nation must ensure that every willing Indian citizen, as prioritized by the Government ultimately gets access to the vaccine, without any fear or favor and more importantly without any discrimination based on region, gender, religion or social status. It is also important for the scientific community as well as the policy makers to view the process of vaccination as a tool for promoting health equity and executing this initiative well, will safeguard the health of our citizens as well as our economy. 
While writing this manuscript I am sorry to pendown the sad demise of Cancer Crusader Dr.V.Shantha, Chairman Adyar Cancer Institute, Chennai - India. (At the age of 94 years) She is the cancer crusader, work more than 65 years at the Institute brought revalution and evalution in the management of cancer in the country. For her extrordinary cotribution she was recognised with padma Vibhushan, Padmabhushan, Padmashri from Government of India. She received The Asian Nobel - the Ramon Magsasay award for public service in 2005 .

Finally, I thank the editorial board \& Executive committee members of IASO Special thanks to Dr. K. Harish, Dr.Arvind S Kapali, Dr.Narendra Hulkal, Dr.Arvind Krishnamurthy for their continuous involvement with the editorial office. I thank the editorial board, office of IJSO Mr. Suresha J, Dr. Shivananda Swamy whose hard work as given an outstanding status for the journal.

We acknowledge the support of our publisher team Springer.

\section{References}

1. Desai S, Gupta A IASO COVID-19 Guidelines (Updated on 9th April 2020). IJSO 11(2):171-174

2. Krishnamurthy A, Gopinath KS (2020) The Need for Prioritizing Cancer Surgeries Amidst the COVID-19 Pandemic. IJSO 11(2): 169-170

3. Deo SVS et al (2020) Guiding Principles for Cancer Surgery during the COVID-19 Pandemic. IJSO 11((1) E):3-10

4. Role of Positron Emission Tomography/Computed Tomography in Preoperative Assessment of Carcinoma Endometrium-a Retrospective Analysis Rohini Kulkarni ${ }^{1,2}$ Rani Akhil Bhat, ${ }^{2}$ Vibhawari Dhakharia, ${ }^{2}$ Kumar Kallur, ${ }^{3}$ and Aparna Gangoli ${ }^{4}$ Indian J Surg Oncol 2019 Mar; 10(1): 225-231

5. ESGO/ESTRO/ESP guidelines for the management of patients with endometrial carcinoma citation 64 Concin N, et al, Int J Gynecol Cancer,2020;0:12-39. doi:https://doi.org/10.1136/ijgc-2020002230,31

Publisher's Note Springer Nature remains neutral with regard to jurisdictional claims in published maps and institutional affiliations. 